\title{
SIMULATION OF TANK TRUCK LOADING OPERATIONS IN A FUEL DISTRIBUTION TERMINAL
}

\author{
Reis, A. N.*; Pitombeira-Neto, A. R. ${ }^{* *} \&$ Rolim, G. A. ${ }^{* *}$ \\ * Raízen, Av. José Sabóia, 303, Fortaleza, Brazil \\ ** Department of Industrial Engineering, Federal University of Ceará, Fortaleza, Brazil \\ E-Mail: arthurnoroes@gmail.com, anselmo.pitombeira@ufc.br, gustavorolim@alu.ufc.br
}

\begin{abstract}
Tank truck loading operations in fuel distribution terminals have particular characteristics which are challenging to simulate. Demands for different fuel types are correlated rather than independent. In addition, queuing policies which do not address the current state of the terminal may increase equipment idleness and trucks' lead time. We propose a decomposition of the joint probability distribution of fuel types and a procedure to simulate it. We also propose a new queuing policy aimed at reducing equipment idleness and trucks' lead time. The procedures are tested and validated through a discrete-event simulation model of a real fuel distribution terminal. We simulate alternative scenarios in which we increase fuel flow rate as well as the number of loading arms and test a new queuing policy. Results show the effectiveness of the simulation procedure in replicating real performance indicators. Moreover, the proposed idleness-based queuing policy resulted in lower idleness and lead time compared with a first-come-first-served policy.

(Received in December 2016, accepted in April 2017. This paper was with the authors 1 month for 3 revisions.)
\end{abstract}

Key Words: Tank Truck, Fuel Loading Operations, Scheduling, Queuing Policy, Discrete-Event Simulation

\section{INTRODUCTION}

The distribution of petroleum products represents an important stage in the oil industry supply chain. It encompasses two major distribution paths in the chain: shipping of light products, such as gasoline and diesel, from refineries to distribution terminals; and shipping of heavy products to industrial customers and lube plants $[1,2]$. In distribution terminals, tank trucks are loaded with specific fuel types in order to meet customer's demand.

Most research on petroleum product distribution focuses on shipping from refineries to distribution terminals, or on routing trucks from terminals to petrol stations. In this paper, we study the problem of tank truck scheduling in a fuel distribution terminal. Before dispatching trucks to petrol stations, they have to be loaded with different fuel sets. Loading operations involve the use of equipment such as loading racks. Trucks wait in a queue before they are assigned to a free platform in which they can use a loading arm to fill the tank compartments. Operations should be managed to keep lead times as low as possible while equipment utilisation should be high. Similar operations occur in container terminals and in the mining industry.

Despite the practical importance of loading operations in fuel distribution terminals, we are unaware of any simulation study on this topic. The objective of this paper is to propose a simulation approach to the tank truck loading problem. We developed a model to simulate loading operations, which include the arrival of trucks at the terminal, fuel demand generation, and truck scheduling. In particular, the contributions of our paper are the following:

- a description of truck loading operations in fuel distribution terminals and related problems;

- a procedure for sampling from the multivariate distribution of fuel demand; 
- a proposal of a new queuing policy in order to reduce equipment idleness;

- results from a discrete-event simulation model developed for a real case study.

This paper is subdivided as follows: Section 2 reviews literature; Section 3 presents the research problem; Section 4 describes the solution approach; Sections 5 and 6 respectively describe the case study and the simulation of alternative scenarios; Section 7 draws some conclusions and comments on future research.

\section{LITERATURE REVIEW}

Simulation analysis is a key tool in assessing performance of production systems, which mainly involve stochastic factors. Seebacher et al. [3] describe a simulation-based approach for the valuation of in-plant logistics efficiency. Burinskiene [4] develops a simulation model for the evaluation of alternative methods for routing forklifts in warehouses. Lerher et al. [5] present a simulation study for the performance analysis of automated storage and retrieval systems.

As we have stated in the last section, there is scarce literature specifically on the problem we address. We then refer to research on related problems, such as truck routing, truck scheduling, and simulation of operations in container terminals and mines. Cafaro et al. [6] describe a discrete-event simulation (DES) model in order to schedule the delivery of multiple petroleum products from a refinery to a terminal through a pipeline. Cafaro and Cerdá [7] propose a mixed integer linear programming model to dynamically schedule multiproduct pipelines, while Relvas et al. [8] develop an integrated approach to scheduling and managing inventory for the distribution of oil products.

Routing trucks from terminals to petrol stations is commonly referred to as truck dispatching. Brown and Graves [9] describe an automated system for real-time scheduling and dispatching of tank trucks. Brown et al. [10] describe a decision support system which integrates a collection of integer programming models for the dispatching of trucks to petrol stations. Russell and Chalinor [11] propose a greedy algorithm for scheduling trucks used in the pickup and delivery of crude oil. $\mathrm{Ng}$ et al. [12] develop a decision support system to the assignment and routing of tank trucks. Cornillier et al. [13] propose a heuristic for the multiperiod petrol station replenishment problem, while Benantar et al. [14] formulate the problem taking into account multi-compartment trucks and time windows. Other noteworthy contributions in this area include the ones by Xiao and Rao [15] and Cornillier et al. [16].

Operations in terminals are complex and the use of analysis tools such as simulation can greatly support performance improvement. Examples are container terminals, where operations management has benefited from the use of simulation. Iannone et al. [17] propose a discrete-event simulation model to support decisions on vehicle handling in a roll-on/rolloff terminal. Zhang et al. [18] describe an integrated approach to scheduling container terminals with dual-cycle operations. Lin et al. [19] evaluate alternative investment options in a container terminal with the use of a simulation model for crane scheduling. Cartenì and de Luca [20] apply a simulation model to estimate handling activity time duration in a container terminal. Legato and Mazza [21] develop a simulation-based queuing network model to simulate complex priority rules for resource allocation, while a comprehensive literature review on the application of simulation to performance analysis of terminal operations can be found in Cartenì and de Luca [22].

Mining operations is another field in which truck scheduling is a critical activity. Runciman et al. [23] carry out a simulation study in order to evaluate the performance of truck loading operations in an underground mine. Meng et al. [24] develop a modelling framework in order to simulate the scheduling of material handling equipment in an open pit mine. Through a simulation model, Soofastaei et al. [25] assess the effect of truck load on 
productivity and fuel consumption in a surface mine. Hashemi and Sattarvand [26] use simulation to evaluate productivity of alternative scheduling of trucks to loaders in a copper mine.

In the next section, we describe the problem we face in simulating the scheduling of trucks to loading stations in a fuel distribution terminal.

\section{PROBLEM STATEMENT}

A fuel distribution terminal is a place where tank trucks load fuel in order to meet replenish orders from petrol stations. A truck may load and carry multiple fuel types, each one in a different compartment. The number of compartments in a truck may vary according to its particular characteristics. A distribution terminal is typically composed of stations, where the loading racks are positioned. Each loading rack has two platforms and loading arms for pumping different fuel types, such as gasoline, diesel, and ethanol. Trucks arrive and look for available platforms in order to load fuels allocated to customers' demands. Each rack may simultaneously load up to two trucks. When there is no platform available, trucks must wait in a queue. Fig. 1 schematically illustrates loading operations at platforms.

Simulation of such loading operations is not trivial, since truck arrivals and their fuel demands are stochastic. In particular, a given truck demands a set of fuel types with different volumes. There are three random variables associated with a particular truck: the number of compartments, the fuel set to be loaded, and the vector of volumes to be loaded associated with a fuel set. In practice, fuel types demanded by trucks are interdependent. For example, the probability of a truck demanding gasoline and diesel is not equal to the product of the marginal probabilities of demanding these fuel types. For this reason, in contrast to most simulation models, we cannot model fuel types as independent. We must specify a joint probability distribution for fuel sets.

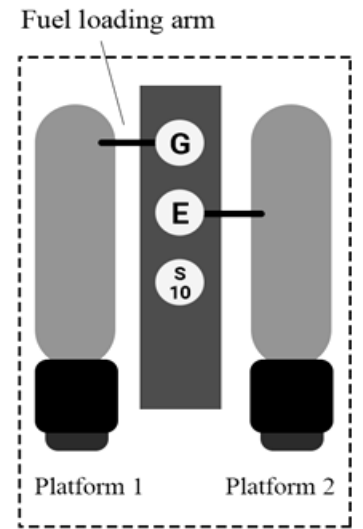

STATION 1

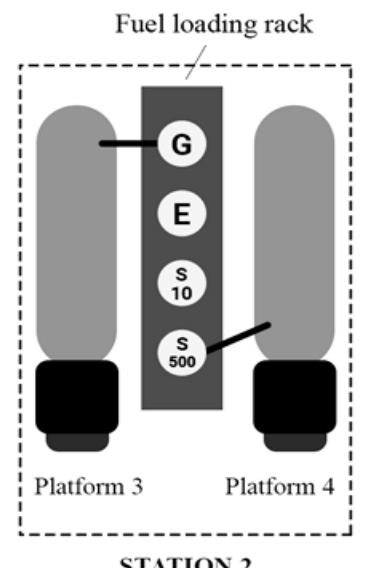

STATION 2

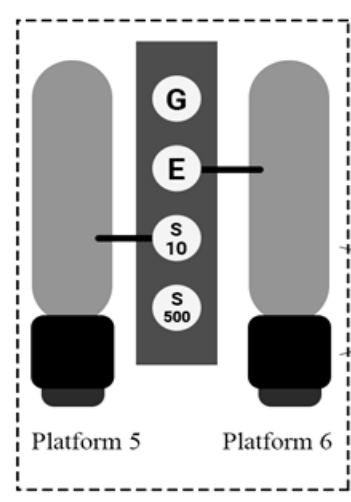

STATION 3

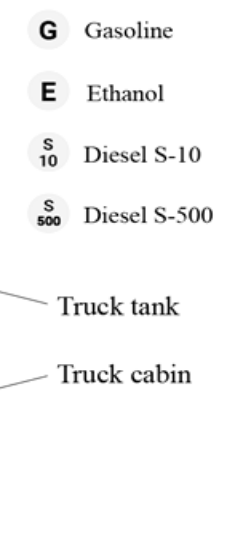

Figure 1: Fuel loading platforms and racks' layout at the terminal under study.

An additional problem is related to the queuing policy. When a platform is released, a first-come-first-serviced (FCFS) policy selects the truck with the longest waiting time to start loading. However, FCFS does not consider the current state of the loading racks. For example, as a rack may simultaneously load two trucks, it may be the case that both trucks have to load the same fuel type. When this is the case, one of the trucks has to wait at the platform for the other to finish loading. This situation is illustrated in Fig. 2. In this example, truck A was already loading ethanol in platform 1 of the loading rack when platform 2 was released. Then truck B started loading gasoline. When truck A finishes loading ethanol and needs to load gasoline, the loading arm is busy with truck B and truck A has to wait. This increases loading time of truck A and also increases idleness of loading racks. 

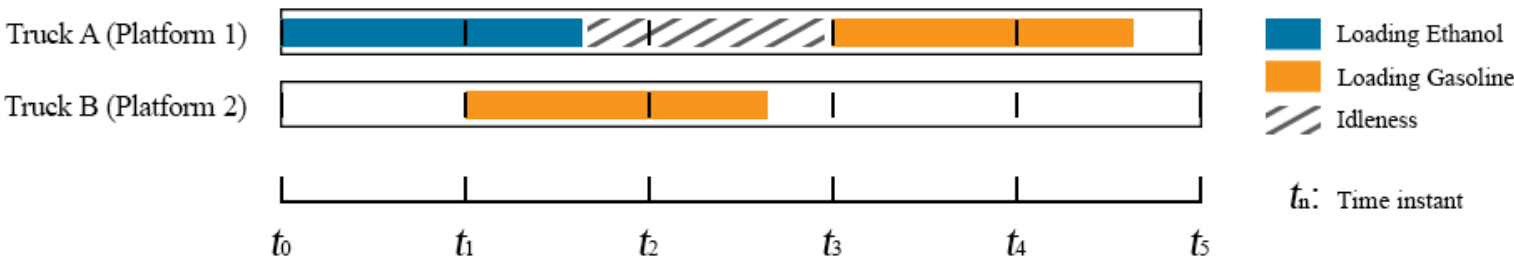

tr: Time instant

Figure 2: Truck A stays idle waiting for truck B to finish gasoline loading.

\section{SOLUTION APPROACH}

In this section, we detail our solution approach in order to tackle the problems described in Section 3. In Section 4.1 we approach the problem of simulating tank truck demands for fuel and in Section 4.2 we propose a queuing policy to reduce equipment idleness.

\subsection{Simulation of fuel demand}

The main hurdle in simulating fuel demand in the case of terminal operations is that fuel types demanded by a tank truck are not independent. Let us first define some random variables associated with a given truck: $N$ : number of compartments; $S$ : set of fuel types demanded; $V_{j}$ : volume of compartment $j, j=1, \ldots, N$.

$N$ is a discrete variable ranging from 1 to some upper bound $N^{\max }$ depending on the truck models operated in the specific distribution terminal. $S$ is a set of fuels demanded by a given truck. For example, a realized set $s$ may include gasoline and ethanol, i. e., $s=\{$ gasoline, ethanol\}. The sample space for $S$ is discrete and includes all possible fuel combinations from a base set of fuels. $V_{j}$ is the volume capacity of the given truck compartment. If a truck has $n$ compartments, then $V_{1}, V_{2}, \ldots, V_{n}$ are random variables associated with the volumes of each compartment.

Let $p\left(n, s, v_{1}, v_{2}, \ldots, v_{n}\right)$ be the joint probability distribution of the random variables associated with a truck's demand for fuel. In order to sample from this distribution, we make the following decomposition of the joint distribution into conditional distributions:

$$
p\left(n, s, v_{1}, v_{2}, \ldots, v_{n}\right)=p\left(v_{1}, v_{2}, \ldots, v_{n} \mid n, s\right) p(n \mid s) p(s)
$$

In addition, we assume that compartment volumes are mutually independent and each volume $v_{j}$ is dependent only on the number of compartments $n$ :

$$
p\left(n, s, v_{1}, v_{2}, \ldots, v_{n}\right)=\prod_{j=1}^{n} p\left(v_{j} \mid n\right) p(n \mid s) p(s)
$$

Therefore, sampling from the joint distribution is equivalent to sampling from the conditional distributions given in Eq. (2). Fig. 3 shows the sampling procedure. The particular method to sample from the conditional distributions given in Fig. 3 will depend on the particular probability distributions chosen. In Section 5 we discuss the adopted probability distributions in the case study.

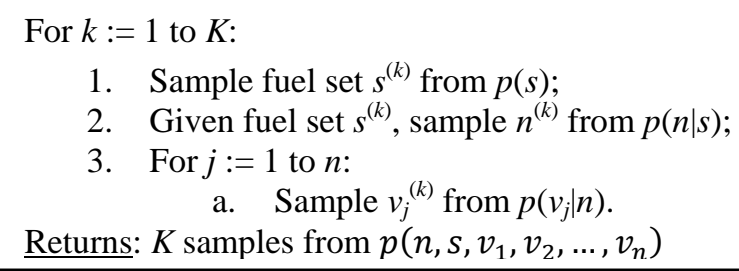

Figure 3: Procedure for sampling from the joint distribution of fuel demand. 


\subsection{A queuing policy aimed at reducing idleness}

As stated in Section 3, FCFS queuing policy is myopic in the sense that it does not consider the current state of the platforms and may result in high idleness of the loading racks. We then devised a queuing policy based on an idleness indicator associated with a pair of tank trucks. Let $A=\left[a_{1}, a_{2}, \ldots, a_{m}\right]$ and $B=\left[b_{1}, b_{2}, \ldots, b_{m}\right]$ be the vectors of fuel volumes demanded by two tank trucks $\mathrm{A}$ and $\mathrm{B}$, where $a_{i}$ and $b_{i}$ denote the volumes of fuel of type $i$ demanded by trucks $\mathrm{A}$ and $\mathrm{B}$ and $m$ is the number of fuel types. If trucks $\mathrm{A}$ and $\mathrm{B}$ were to be loaded in the same platform, they would produce an idleness indicator $I_{A B}$. In principle, this indicator should be measured in time units and it would indicate how much time the trucks have to wait for the other to finish loading. As fuel flow rates are constant in general, the total volume a truck loads while the other truck waits is directly proportional to the waiting time. $I_{A B}$ is then measured in volume units (e. g., $\mathrm{m}^{3}$ ). $I_{A B}=0$ means that trucks A or B both can load all required fuels simultaneously in the same platform with no idleness. Fig. 2 illustrates an example in which $I_{A B}>0$. Given two trucks with volume vectors $A$ and $B, I_{A B}$ can be calculated by means of the procedure given in Fig. 4.

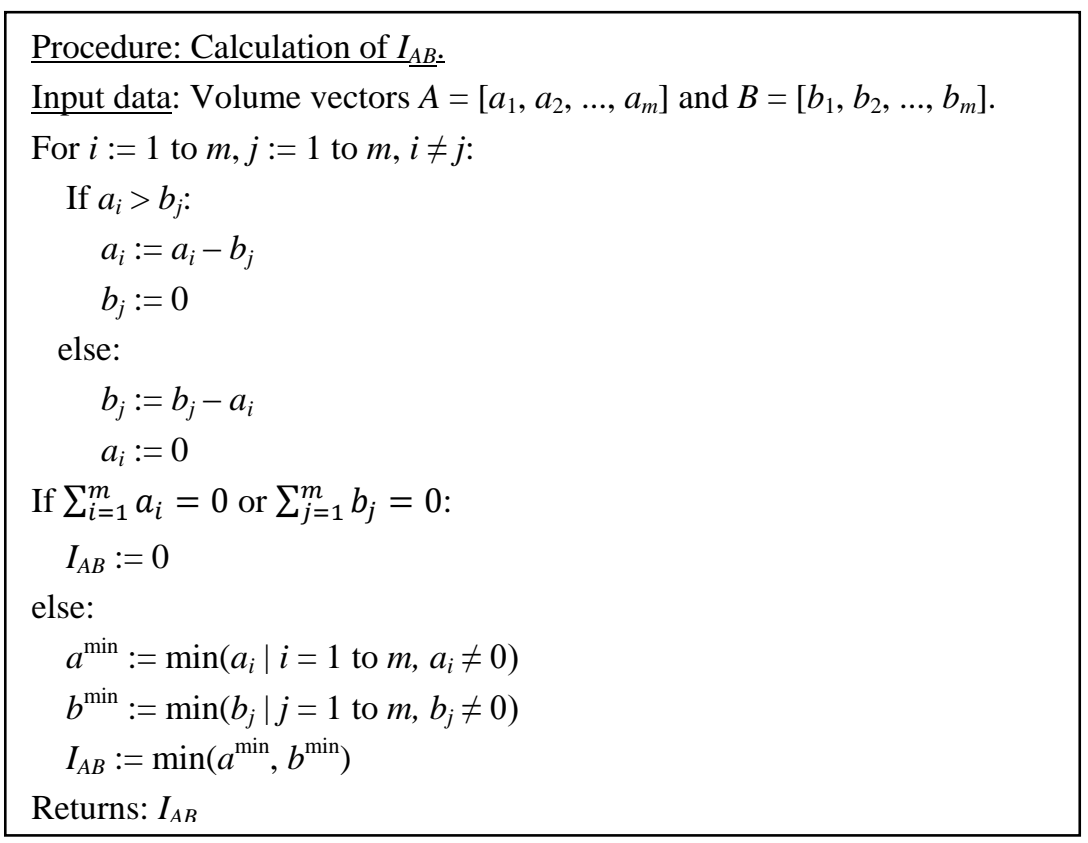

Figure 4: Procedure to calculate idleness indicator $I_{A B}$.

1. Order all trucks in queue in decreasing order of waiting time; Let $A(i)$ be the truck in the $i^{\text {th }}$ order in queue; Make $i=1$ and $A=A(i)$

2. Calculate $I_{A B}$, where $B$ is the truck currently loading in the platform;

3. If $I_{A B}<t$, assign truck $A$ to the platform;

Else $i=i+1$ and $A=A(i)$; Go to step 2;

4. If no truck in queue satisfy $I_{A B}<t$, resort to FCFS policy.

Figure 5: Proposed idleness-based queuing policy.

The new proposed idleness-based queuing policy is described in Fig. 5. Let $t$ be a specified threshold volume, equivalent to a maximum acceptable "idleness", in which idleness is measured in terms of the fuel quantity (volume) a loading arm could pump if it was not idle. The policy selects from the queue a truck whose $I_{A B}$ is smaller than $t$. If no truck satisfies this condition, the policy resorts to FCFS. Then, under this idleness-based policy, the idea is to choose a truck from the queue whose loading operations will result in lower idleness of the loading arms when compared with FCFS. 


\section{CASE STUDY}

In this section, we describe a real case study for which we developed a simulation project using the solution approach proposed in Section 4. Section 5.1 gives an overview of the main processes considered while developing the model, Section 5.2 outlines truck arrivals and its stochastic nature, Section 5.3 considers the modelling of fuel demand, Section 5.4 describes activity delays as well as possible loading failures and interruptions, and lastly Section 5.5 addresses model building and validation.

\subsection{Process description}

The facility under study is an important fuel distribution terminal located in Brazil. It is composed of 3 fuel loading stations, each with a single loading rack. Each rack can load up to 2 trucks at the same time depending on the truck compartment settings. One of the racks has 3 fuel loading arms while the other two racks have 4 arms. Each loading arm is associated with a specific fuel type: diesel S-10 (S10), diesel S-500 (S500), gasoline (G) and ethanol (E). The layout was previously shown in Fig. 1. The activities that occur within the fuel distribution terminal are described in Fig. 6 by using Business Process Model Notation (BPMN).

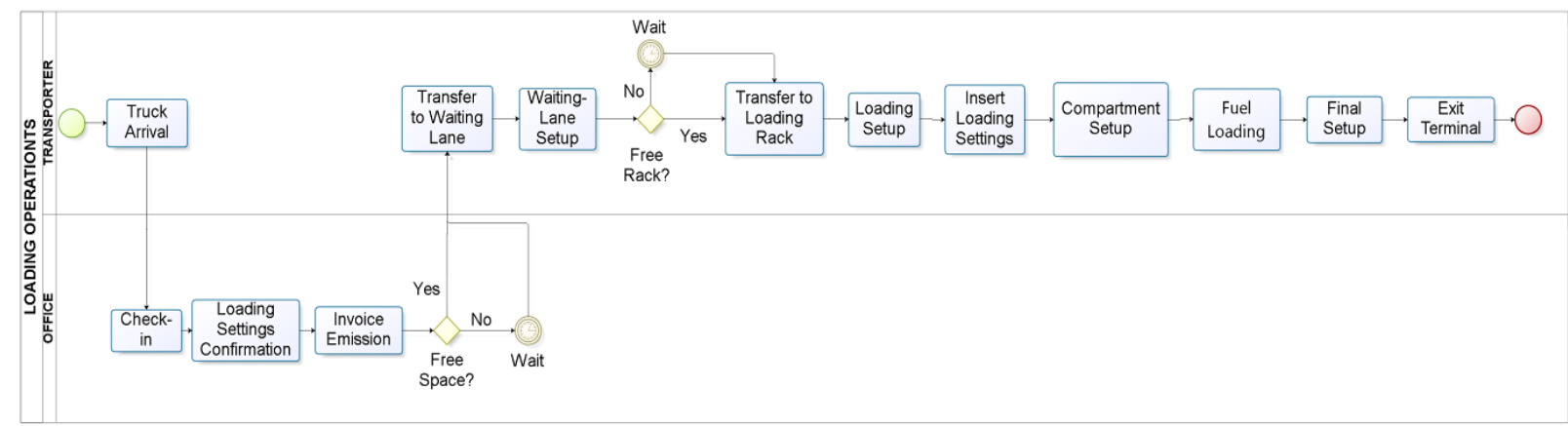

Figure 6: Loading operations within the terminal.

\subsection{Truck arrivals}

The terminal operates 3 types of freight: Cost, Insurance and Freight (CIF); Free on Board (FOB), and Congener (CON). The terminal daily schedule starts at 00:00 in the morning and ends at 20:00. Truck arrival rates are non-stationary over the day. We then modelled interarrival times in intervals of one hour. For each of the 3 freight categories, a statistical analysis was performed based on 3-month data collected from the terminal's data base. For FOB and CON freights, there were large samples available and we managed to fit probability densities by using ExpertFit software. All probability densities passed Kolmogorov-Smirnov (KS) and chi-square hypothesis tests with $p$-values greater than 0.05 in all cases. The samples for CIF freights interarrival times were not sufficient to adequately fit a theoretical distribution or to use an empirical distribution. In this case, we assumed that interarrival times are exponential for all time intervals with mean arrival rates estimated from the available samples. The probability distributions are given in Table I, where we adopt the following notation: $\quad \mathrm{P}-$ Pearsont6,

$$
\begin{aligned}
& \text { JB - Johnson Bounded, } \\
& \text { Ga - gamma, } \\
& \text { B - beta, } \\
& \text { W - Weibull, } \\
& \text { Ex - exponential and } \\
& \text { Er - Erlang. }
\end{aligned}
$$


Table I: Truck interarrival time distributions.

\begin{tabular}{|c|c|c|c|}
\hline $\begin{array}{c}\text { Time interval } \\
\text { starting at }\end{array}$ & FOB (distribution) & CON (distribution) & $\begin{array}{c}\text { CIF (mean } \\
\text { arrival rate) }\end{array}$ \\
\hline 0:00 & $\mathrm{P}(6.12,611.44,1.19,3.23)$ & - & 4 \\
\hline 1:00 & $\mathrm{JB}(0.04,3511.65,1.22,0.61)$ & - & 2 \\
\hline 2:00 & $\mathrm{P}(0.00,81329.54,0.10,99.73)$ & $\mathrm{P}(0.00,51508.36,1.24,99.70)$ & 1 \\
\hline 3:00 & $\operatorname{Ex}(0.00,888.24)$ & $\mathrm{P}(0.62,12116.40,1.12,13.34)$ & 1 \\
\hline 4:00 & $\operatorname{Ex}(0.24,928.71)$ & $\mathrm{JB}(0.79,14668.80,2.43,0.87)$ & 0 \\
\hline $5: 00$ & $\mathrm{P}(0.24,10102.19,1.06,18.12)$ & $\mathrm{P}(0.00,2619.75,1.61,5.68)$ & 0 \\
\hline $6: 00$ & $\operatorname{Er}(11.82,819.82,1.00)$ & $\mathrm{B}(12.70,14142.24,1.00,10.38)$ & 1 \\
\hline 7:00 & $\operatorname{Er}(21.70,1065.51,1.00)$ & $\mathrm{Ga}(0.00,897.04,1.64)$ & 1 \\
\hline $8: 00$ & $\mathrm{Ga}(0.03,808.32,1.31)$ & $\mathrm{JB}(102.09,9392.66,0.78,0.72)$ & 2 \\
\hline 9:00 & $\mathrm{JB}(0.07,3882.63,0.94,0.69)$ & $\mathrm{JB}(12.26,11612.26,1.16,0.59)$ & 1 \\
\hline $10: 00$ & $\mathrm{P}(4.96,70372.06,1.22,99.95)$ & $\mathrm{W}(0.00,1602.40,0.92)$ & 1 \\
\hline $11: 00$ & $\mathrm{JB}(0.03,4181.78,1.20,0.81)$ & $\operatorname{Ex}(0.00,1827.48)$ & 1 \\
\hline $12: 00$ & $\mathrm{Ga}(4.22,991.10,0.97)$ & $\mathrm{P}(0.00,18687.12,1.21,12.40)$ & 1 \\
\hline 13:00 & $\mathrm{W}(0.00,1026.59,1.11)$ & $\mathrm{B}(0.38,11857.70,1.23,5.92)$ & 1 \\
\hline $14: 00$ & $\mathrm{Ga}(0.00,1065.63,0.96)$ & $\mathrm{P}(9.88,180448.51,1.24,99.96)$ & 1 \\
\hline $15: 00$ & $\mathrm{~B}(0.21,7109.48,1.06,7.04)$ & $\mathrm{P}(8.77,9941.52,1.15,7.24)$ & 1 \\
\hline $16: 00$ & $\operatorname{Ex}(1.42,817.19)$ & $\mathrm{P}(0.00,81888.22,1.14,5.46)$ & 0 \\
\hline $17: 00$ & $\mathrm{~W}(12.40,1005.98,1.12)$ & $\mathrm{JB}(236.30,17914.60,1.56,0.73)$ & 0 \\
\hline $18: 00$ & $\operatorname{Ex}(0.00,1125.20)$ & - & 0 \\
\hline 19:00 & $\mathrm{JB}(0.45,3682.89,0.46,0.64)$ & - & 3 \\
\hline
\end{tabular}

\subsection{Modelling of fuel demand}

After arrival, trucks wait for load programming. This involves defining the fuel types, how many truck compartments will be loaded, and the volumes to be loaded. These characteristics are specified by managers based on circumstantial factors, such as customers demand, product availability, and trucks' characteristics. We used historical data of truck loads from the past three months prior to the study, which were stored in the enterprise's data base. We then used this data to specify the probability distributions $p(s), p(n \mid s)$ and $p\left(v_{j} \mid n\right)$, defined in Section 3.

Regarding $p(s)$, the probability of occurrence of a fuel set $s$, we enumerated all fuel sets observed in the data and computed their relative frequency. As we were not able to fit a suitable parametric probability distribution, we resorted to an empirical distribution, given in Table II. In the case of $p(n \mid s)$, the number of a trucks' compartments given fuel set, we used binomial distributions for fuel sets $\{$ S500 $\}$ and $\{$ S500, E $\}$ while trucks loaded with fuel sets $\{\mathrm{E}\}$ and $\{\mathrm{S} 500, \mathrm{E}\}$ presented a deterministic number of compartments. For the remaining fuel sets, we noticed binomial or multinomial distributions did not provide good fit. We then calculated the relative frequency for the number of compartments given each observed fuel set and used them as empirical probability distributions. Finally, we assumed that probability distributions of truck compartments' volumes are equal, so as to $p\left(v_{1} \mid n\right)=p\left(v_{2} \mid n\right)=\ldots=$ $p\left(v_{n} \mid n\right)=p(v \mid n)$. We also specified an empirical distribution for $p(v \mid n)$ (see Table III). 
Table II: Possible fuel sets.

\begin{tabular}{|c|c|c|}
\hline Probability & $\begin{array}{c}\text { Cumulative } \\
\text { probability }\end{array}$ & Set \\
\hline 0.2882 & 0.2882 & G, S10 \\
\hline 0.1907 & 0.4789 & G, S10, E \\
\hline 0.1119 & 0.5908 & G \\
\hline 0.1077 & 0.6985 & G, E \\
\hline 0.0877 & 0.7862 & G, S10, S500 \\
\hline 0.0861 & 0.8724 & S10 \\
\hline 0.0608 & 0.9331 & G, S500 \\
\hline 0.0158 & 0.9490 & All \\
\hline 0.0141 & 0.9631 & S10, S500 \\
\hline 0.0139 & 0.9770 & G, S500, E \\
\hline 0.0104 & 0.9874 & S500 \\
\hline 0.0081 & 0.9956 & S10, E \\
\hline 0.0023 & 0.9978 & E \\
\hline 0.0012 & 0.9991 & S10, S500, E \\
\hline 0.0009 & 1.0000 & S500, E \\
\hline
\end{tabular}

Table III: Probability of a tank's compartment volume.

\begin{tabular}{|c|c|c|}
\hline Probability & $\begin{array}{c}\text { Cumulative } \\
\text { probability }\end{array}$ & $\begin{array}{c}\text { Compartment's } \\
\text { volume (L) }\end{array}$ \\
\hline 0.8979 & 0.8979 & 5000 \\
\hline 0.0356 & 0.9336 & 3000 \\
\hline 0.0247 & 0.9582 & 10000 \\
\hline 0.0130 & 0.9712 & 4000 \\
\hline 0.0110 & 0.9822 & 8000 \\
\hline 0.0096 & 0.9918 & 6000 \\
\hline 0.0082 & 1.0000 & 7000 \\
\hline
\end{tabular}

Table IV: Probability distributions of activities' delays.

\begin{tabular}{|l|c|}
\hline \multicolumn{1}{|c|}{ Activity } & Distribution \\
\hline Transfer to waiting lane & Beta $(49.04,64.36,1.98,1.49)$ \\
\hline Waiting-lane setup & Log-Logistic $(0.00,179.18,8.62)$ \\
\hline Transfer to loading rack & Beta $(66.46,81.92,2.22,4.41)$ \\
\hline Loading setup & Erlang $(0.30,1.93,99.00)$ \\
\hline Insert load settings into the system & Erlang $(10.59,0.12,209.00)$ \\
\hline Fuel loading & Deterministic \\
\hline Compartment setup & Pearsont5 $(77.44,50.11,3.08)$ \\
\hline Final setup & Johnson Bounded $(117.56,273.70,0.09,1.28)$ \\
\hline Exit terminal & Beta $(32.42,39.26,2.07,1.29)$ \\
\hline
\end{tabular}

\subsection{Activity delays and loading interruptions}

The documentation checking process is composed of 3 sequential activities: check-in, load settings/programming confirmation, and invoice emission. The enterprise's database registered the aggregated processing time for all three activities in which we managed to fit a Beta distribution. The remaining activities performed at the terminal did not have times registered in a database. We then manually took 20 samples of the delays of each activity, except for the fuel loading activity, whose time duration is a deterministic function of the total 
volume to be loaded and equipment flow rates. These flow rates vary according to the fuel type to be loaded. Table IV shows the fitted probability distributions. All passed KS tests with $p$-values $>0.05$.

\subsection{Model building and validation}

A discrete-event simulation model was created to represent the processes and truck flow within the fuel distribution terminal by means of FlexSim simulation package. We used Flexscript to code the logic of the idleness-based queuing policy proposed in Section 4.2. Trucks are modelled as entities and loading racks are modelled as resources. In addition, we adopted the following assumptions:

- demand variability caused by exogenous factors such as changes in fuel prices, seasonality and product availability were not taken into account;

- fuel flow rates were assumed constant. In practice, there is some variability in flow rates due to factors such as equipment condition and fuel level inside the tank, but these can be considered negligible for simulation purposes;

- breakdowns, failure in truck engines, tank inspections, and other random events with low probability of occurrence were not considered in this model.

In order to test whether our model emulated the behaviour of the real system, we applied historical data validation [27]. Three-month historical data selected from the terminal's data base were used to calculate the following indicators: gate-to-gate $(G 2 G)$, which is the lead time of trucks from arrival to departure, total number of trucks serviced (TS), and total volume loaded $(V)$. Table $\mathrm{V}$ shows a comparison between the performance indicators of the real system and the results obtained with the simulation model. As there were no significant differences between output values from the simulation model and the values calculated from historical data, we considered the model as validated.

Table V: Comparison of average performance indicators between real system and simulation model (95\% confidence level).

\begin{tabular}{|c|c|c|}
\hline Performance indicator & Real system & Simulation model \\
\hline$G 2 G(\mathrm{~min})$ & 80.6 & $78.2(74.5,81.9)$ \\
\hline$T S$ & 127.3 & $125.2(122.0,132.7)$ \\
\hline$V\left(\mathrm{~m}^{3}\right)$ & 2935000 & $3033455(2926773,3140136)$ \\
\hline
\end{tabular}

\section{SIMULATION OF ALTERNATIVE SCENARIOS}

The following sections describe alternative scenarios and the results that were achieved. Section 6.1 addresses possible impacts if the fuel flow rates are changed, Section 6.2 evaluates the effects of adding an extra fuel loading arm to a rack, and finally, Section 6.3 compares results of applying the idleness-based queuing policy rule with the FCFS rule.

\subsection{Increase in fuel flow rate}

Increasing fuel flow rate directly influences fuel loading efficiency. Our study considered a $20 \%$ increase in the flow rate of all fuels one at a time and evaluated its impact on $G 2 G$ and on rack's idleness. As can be seen in Figs. 7 and 8, the greatest improvements on performance indicators occur when gasoline flow rate is increased, followed by diesel S10. In particular, reduction in $G 2 G$ relative to base scenario is approximately 7 and 4 minutes, respectively. Improvements due to increase in the remaining fuels are not statistically significant in relation to base values. A possible explanation might be that gasoline and diesel S10 have higher 
demand in comparison to other fuels. It is also important to mention that idleness rises when the flow rate of S500 is increased. Since S500 volumes are in general lower compared to other fuels, after quickly loading S500 a truck keeps occupying the rack while waiting an available fuel arm to load the remaining compartments with other fuels. This may lead to an increase in rack idleness, reducing the efficiency in infrastructure utilisation.

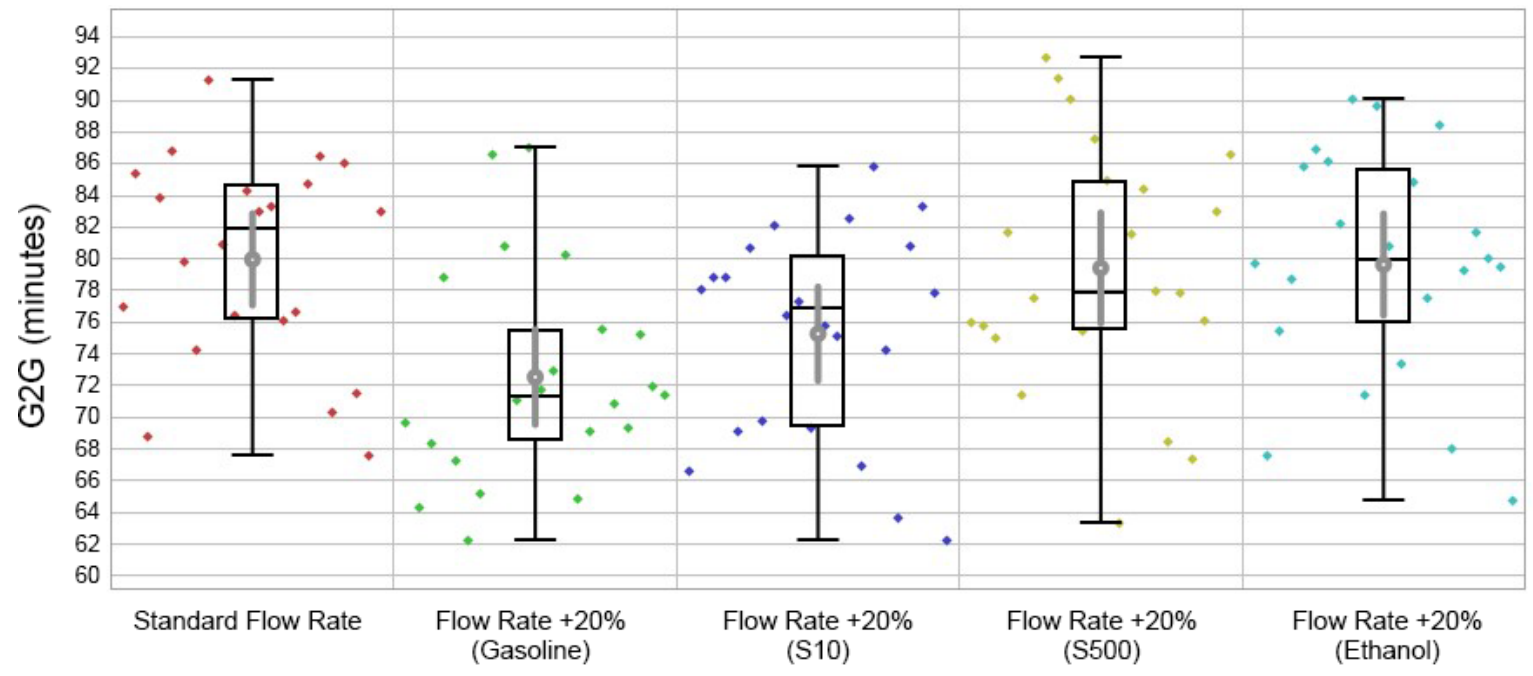

曰 $25 \%$ - 50\% - 75\% I Min - Max $\$$ Mean Confidence Interval

Figure 7: Impact of increasing flow rate on $G 2 G$.

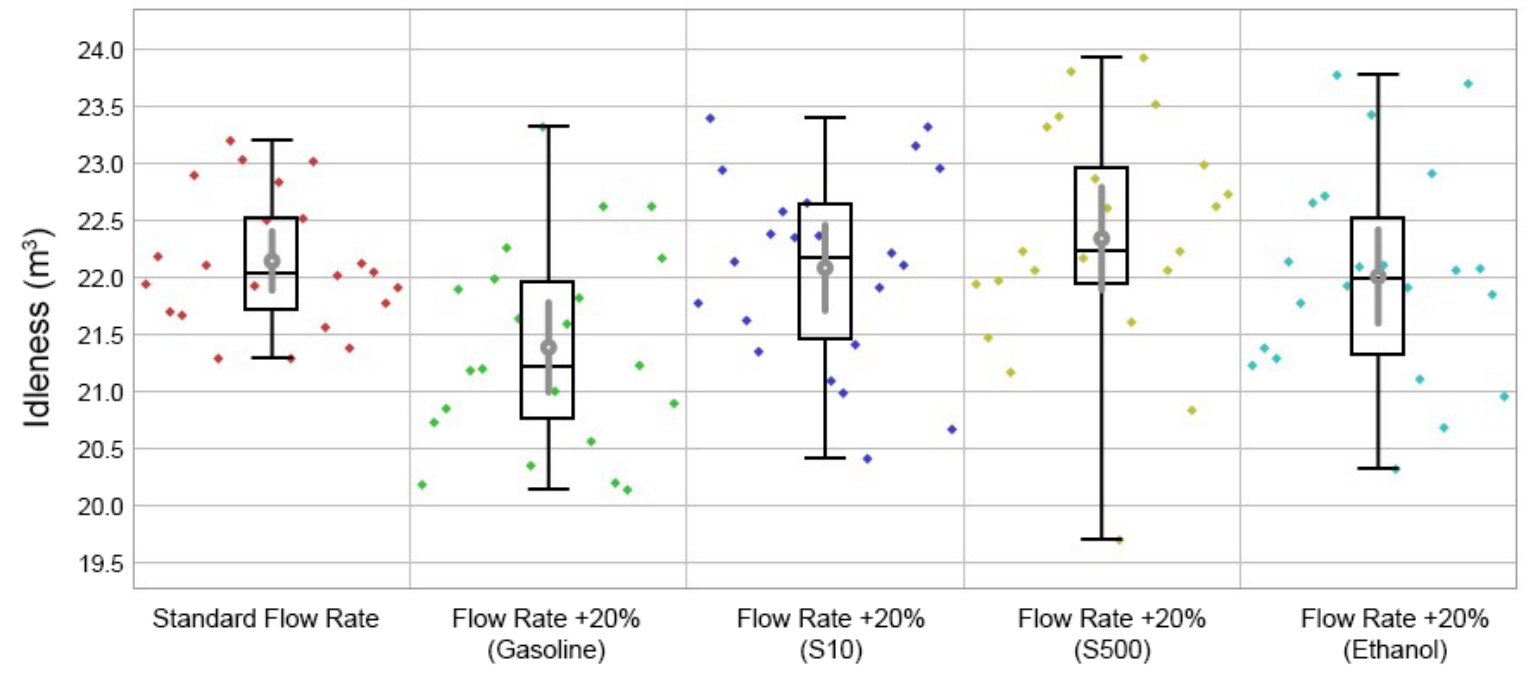

曰 $25 \%-50 \%-75 \%$ I Min - Max $\$$ Mean Confidence Interval

Figure 8: Impact of increasing flow rate on rack's idleness.

\subsection{Additional fuel loading arm}

One of the factors that contributes most to the inefficiencies on loading operations is the idle time of fuel loading arms, which was translated into the idleness indicator. It may occur when two trucks are being loaded in the same rack and both of them share similar compartment settings. In order to reduce idleness and increase the overall efficiency of the system, we considered adding a gasoline loading arm, since it is the most demanded product. Results on $G 2 G$ and idleness are showed in Table VI, which shows a slight reduction over $G 2 G$ and idleness, although it is not as significant as the results obtained from increasing fuel flow rate. It may happen because a loading arm can be added only in one of the racks while the 
increased flow rate has an impact in all of the racks. Moreover, an additional fuel arm is useful when there are two trucks assigned to the same rack that mostly carry gasoline and do not include a sufficient amount of other fuels on their loading configuration so as to allow an alternate use of loading arms.

Table VI: Impact of an additional gasoline arm on performance indicators (95\% confidence intervals).

\begin{tabular}{|c|c|c|}
\hline Performance indicator & With additional loading arm & Without additional loading arm \\
\hline$G 2 G(\mathrm{~min})$ & $76.7(72.9,80.6)$ & $78.2(74.5,81.9)$ \\
\hline Idleness $\left(\mathrm{m}^{3}\right)$ & $21.51(21.14,21.51)$ & $21.7(21.25,21.41)$ \\
\hline
\end{tabular}

\subsection{Application of the idleness-based queuing policy}

In this scenario, we have compared the FCFS queuing policy with the proposed idlenessbased queuing policy as described in Section 4.2. We have varied the threshold volume $t$, in which the unlimited threshold corresponds to the FCFS rule. Fig. 9 shows results for $G 2 G$ and idleness indicators. It can be seen that the idleness indicator decreases with low threshold volumes, achieving the highest value with an unlimited threshold. $G 2 G$ achieves the lowest value with an intermediary threshold of $t=10 \mathrm{~m}^{3}$. Both indicators show that an idlenessbased queuing policy can exhibit better performance than the FCFS policy.
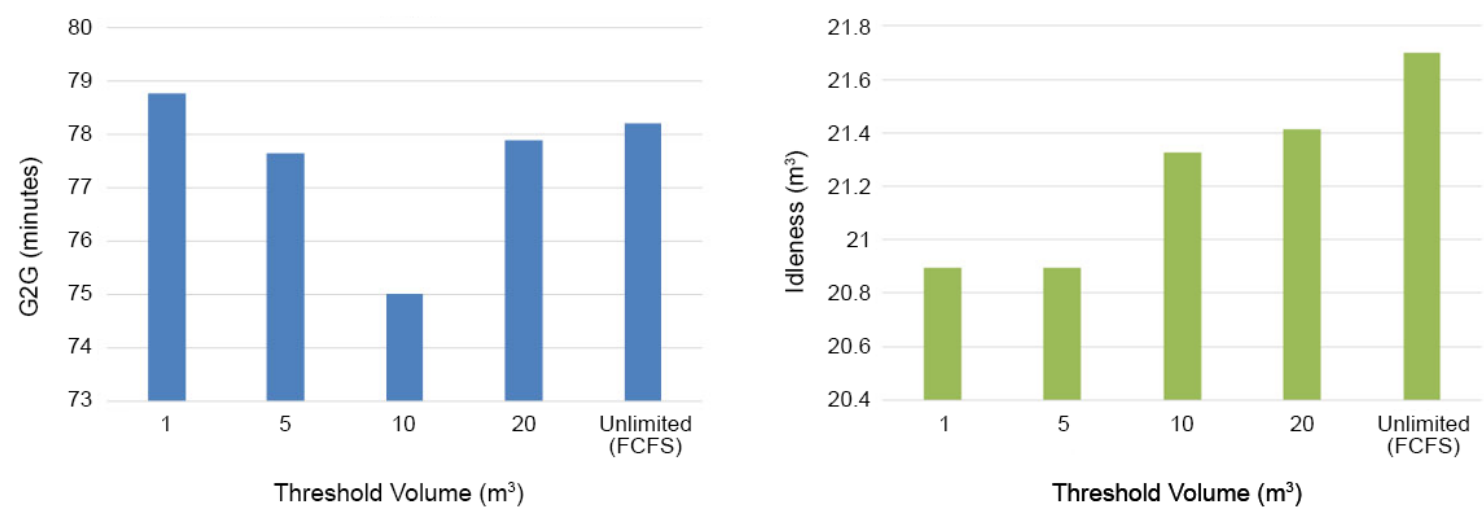

Figure 9: $G 2 G$ and idleness indicators as functions of the threshold volume.

\section{CONCLUSION}

In this paper, we studied the problem of tank truck loading in a fuel distribution terminal. We proposed a procedure to simulate the multivariate distribution of fuel demand and a new queuing policy in order to reduce equipment idleness. We applied the ideas in a simulation model developed for a real case study. Validation of the model showed that the proposed procedure was able to replicate performance indicators from the real system.

In simulated scenarios, the proposed new idleness-based queuing policy resulted in lower $G 2 G$ (lead time) of trucks and lower equipment idleness when compared with a FCFS policy. A possible explanation for the better performance obtained with our proposed policy may lie on the fact that it uses both information on current states of trucks in the queue and information on the state of the terminal, while FCFS policy only takes into account trucks' information. This suggests that a queuing policy which considers the current state of the terminal in addition to trucks' state may produce better performance in practice, although more research studies are required in order to corroborate this hypothesis.

Simulation of alternative scenarios also showed that an increase in gasoline flow rate achieved greater improvements in $G 2 G$ and equipment idleness in comparison with the addition of one more loading arm. However, this result was specific to the case study and we 
cannot state that an increase in flow rates will produce better performance in general. This reassures the importance of using simulation in order to assess the impact on performance by modifying flow rates or changing the number of loading arms.

Finally, we notice that the proposed simulation procedure can be applied to any fuel distribution terminal worldwide which relies on loading racks to load tank trucks. As extensions to this work, we suggest research on alternative queuing policies and use of scheduling algorithms in order to obtain the optimal assignment of trucks to platforms. We also envision the integration of loading operations with the truck dispatching problem in a comprehensive simulation optimisation framework.

\section{ACKNOWLEDGEMENT}

We thank Observatório Tecnológico from Federal University of Ceará for providing access to Flexsim software.

\section{REFERENCES}

[1] Ronen, D. (1995). Dispatching petroleum products, Operations Research, Vol. 43, No. 3, 379387, doi:10.1287/opre.43.3.379

[2] Lima, C.; Relvas, S.; Barbosa-Póvoa, A. P. F. D. (2016). Downstream oil supply chain management: A critical review and future directions, Computers \& Chemical Engineering, Vol. 92, 78-92, doi:10.1016/j.compchemeng.2016.05.002

[3] Seebacher, G.; Winkler, H.; Oberegger, B. (2015). In-plant logistics efficiency valuation using discrete event simulation, International Journal of Simulation Modelling, Vol. 14 , No. 1 , 60-70, doi: $10.2507 / \mathrm{ijsimm} 14(1) 6.289$

[4] Burinskiene, A. (2015). Optimising forklift activities in wide-aisle reference warehouse, International Journal of Simulation Modelling, Vol. 14, No. 4, 621-632, doi:10.2507/ijsimm14(4)5.312

[5] Lerher, T.; Ekren, Y. B.; Sari, Z.; Rosi, B. (2015). Simulation analysis of shuttle based storage and retrieval systems, International Journal of Simulation Modelling, Vol. 14 , No. 1 , 48-59, doi: $10.2507 / \mathrm{ijsimm} 14(1) 5.281$

[6] Cafaro, V. G.; Cafaro, D. C.; Méndez, C. A.; Cerdá, J. (2010). Oil-derivatives pipeline logistics using discrete-event simulation, Proceedings of the 2010 Winter Simulation Conference, 21012113, doi: $10.1109 /$ wsc. 2010.5678864

[7] Cafaro, D. C.; Cerdá, J. (2008). Dynamic scheduling of multiproduct pipelines with multiple delivery due dates, Computers \& Chemical Engineering, Vol. 32, No. 4-5, 728-753, doi:10.1016/j.compchemeng.2007.03.002

[8] Relvas, S.; Magatão, S. N. B.; Barbosa-Póvoa, A. P. F. D.; Neves Jr., F. (2013). Integrated scheduling and inventory management of an oil products distribution system, Omega, Vol. 41, No. 6, 955-968, doi:10.1016/j.omega.2013.01.001

[9] Brown, G. G.; Graves, G. W. (1981). Real-time dispatch of petroleum tank trucks, Management Science, Vol. 27, No. 1, 19-32, doi:10.1287/mnsc.27.1.19

[10] Brown, G. G.; Ellis, C. J.; Graves, G. W.; Ronen, D. (1987). Real-time, wide area dispatch of Mobil tank trucks, Interfaces, Vol. 17, No. 1, 107-120, doi:10.1287/inte.17.1.107

[11] Russell, R. A.; Challinor, P. E. (1988). Effective methods for petroleum tank truck dispatching, Computers \& Operations Research, Vol. 15, No. 4, 323-331, doi:10.1016/0305-0548(88)90016-0

[12] Ng, W. L.; Leung, S. C. H.; Lam, J. K. P.; Pan, S. W. (2008). Petrol delivery tanker assignment and routing: a case study in Hong Kong, Journal of the Operational Research Society, Vol. 59, No. 9, 1191-1200, doi:10.1057/palgrave.jors.2602464

[13] Cornillier, F.; Boctor, F. F.; Laporte, G.; Renaud, J. (2008). A heuristic for the multi-period petrol station replenishment problem, European Journal of Operational Research, Vol. 191, No. 2, 295-305, doi:10.1016/j.ejor.2007.08.016 
[14] Benantar, A.; Ouafi, R.; Boukachour, J. (2016). A petrol station replenishment problem: new variant and formulation, Logistics Research, Vol. 9, No. 6, 18 pages, doi:10.1007/s12159-016$\underline{0133-\mathrm{Z}}$

[15] Xiao, N.; Rao, Y. L. (2016). Multi-product multi-period inventory routing optimization with time window constraints, International Journal of Simulation Modelling, Vol. 15, No. 2, 352-364, doi:10.2507/ijsimm15(2)co8

[16] Cornillier, F.; Laporte, G.; Boctor, F. F.; Renaud, J. (2009). The petrol station replenishment problem with time windows, Computers \& Operations Research, Vol. 36, No. 3, 919-935, doi:10.1016/j.cor.2007.11.007

[17] Iannone, R.; Miranda, S.; Prisco, L.; Riemma, S.; Sarno, D. (2016). Proposal for a flexible discrete event simulation model for assessing the daily operation decisions in a Ro-Ro terminal, Simulation Modelling Practice and Theory, Vol. 61, 28-46, doi:10.1016/j.simpat.2015.11.005

[18] Zhang, Y.; Rong, Z.; Liu, Z.-X. (2014). The integrated scheduling problem in container terminal with dual-cycle operation, International Journal of Simulation Modelling, Vol. 13, No. 3, 335347, doi:10.2507/ijsimm13(3)co12

[19] Lin, J.; Gao, B.; Zhang, C. (2014). Simulation-based investment planning for Humen Port, Simulation Modelling Practice and Theory, Vol. 40, 161-175, doi:10.1016/j.simpat.2013.09.009

[20] Cartenì, A.; de Luca, S. (2012). Tactical and strategic planning for a container terminal: Modelling issues within a discrete event simulation approach, Simulation Modelling Practice and Theory, Vol. 21, No. 1, 123-145, doi:10.1016/j.simpat.2011.10.005

[21] Legato, P.; Mazza, R. M. (2001). Berth planning and resources optimisation at a container terminal via discrete event simulation, European Journal of Operational Research, Vol. 133, No. 3, 537-547, doi:10.1016/S0377-2217(00)00200-9

[22] Cartenì, A.; de Luca, S. (2009). Simulation of a container terminal through a discrete event approach: Literature review and guidelines for application, Proceedings of the 2009 European Transport Conference, 21 pages

[23] Runciman, N.; Vagenas, N.; Corkal, T. (1997). Simulation of haulage truck loading techniques in an underground mine using WITNESS, Simulation, Vol. 68, No. 5, 291-299, doi: $10.1177 / 003754979706800504$

[24] Meng, C.; Nageshwaraniyer, S. S.; Maghsoudi, A.; Son, Y.-J.; Dessureault, S. (2013). Datadriven modeling and simulation framework for material handling systems in coal mines, Computers \& Industrial Engineering, Vol. 64, No. 3, 766-799, doi:10.1016/j.cie.2012.12.017

[25] Soofastaei, A.; Aminossadati, S. M.; Kizil, M. S.; Knights, P. (2016). A discrete-event model to simulate the effect of truck bunching due to payload variance on cycle time, hauled mine materials and fuel consumption, International Journal of Mining Science and Technology, Vol. 26, No. 5, 745-752, doi:10.1016/j.ijmst.2016.05.047

[26] Hashemi, A. S.; Sattarvand, J. (2014). Application of ARENA simulation software for evaluation of open pit mining transportation systems - a case study, Proceedings of the $12^{\text {th }}$ International Symposium Continuous Surface Mining, 213-224, doi:10.1007/978-3-319-12301-1 20

[27] Sargent, R. G. (2005). Verification and validation of simulation models, Proceedings of the 2005 Winter Simulation Conference, 130-143, doi: 10.1109/WSC.2005.1574246 